Research Article

\title{
Otoacoustic emissions in detection of pre-clinical noise induced cochlear damage in military personnel
}

\author{
Abhijeet Bhatia* \\ Department of ENT, Army Hospital (Research and Referral), New Delhi, India \\ Received: 15 September 2015 \\ Accepted: 02 October 2015 \\ *Correspondence: \\ Dr. Abhijeet Bhatia, \\ E-mail: abhijeetbhatia77@gmail.com \\ Copyright: (C) the author(s), publisher and licensee Medip Academy. This is an open-access article distributed under \\ the terms of the Creative Commons Attribution Non-Commercial License, which permits unrestricted non-commercial \\ use, distribution, and reproduction in any medium, provided the original work is properly cited.
}

\begin{abstract}
Background: Objective of current study to analyse the utility of TEOAEs and DPOAEs to detect cochlear damage due to chronic exposure to firearm noise in Indian military personnel at a preclinical stage. Military personnel are exposed to firearm noise and need to be assessed for cochlear damage periodically.

Methods: This cross sectional study was conducted from May 2004 to Apr 2005. Indian army soldiers and general civilian population were included in the study. The TEOAE and DPOAE parameters of two control groups (civilians, no noise exposure, no HL: control group 1; soldiers, noise exposed, hearing loss: Control group 2) were compared with the study group (soldiers, noise exposure, no hearing loss: Study group).

Results: TEOAE amplitudes of the study group varied significantly from those of both the control groups at almost all frequencies. Overall amplitude too followed a similar trend. However, although the DPOAE amplitude of the study group was less than that of control group 1, the difference was not significant. The DPOAE amplitude of study group varied significantly from control group 2 .

Conclusions: TEOAEs proved to be useful to distinguish between green ears and ears chronically exposed to impulse noise with and without hearing loss. But DPOAEs proved to be useful in distinguishing only between normal hearing from hearing loss ears.
\end{abstract}

Keywords: Otoacoustic emission, Noise induced hearing loss, Cochlear dysfunction, Impulse noise

\section{INTRODUCTION}

Excessive noise is one of the most common causes of hearing loss- from military, industrial and recreational sources. According to the World Health Organization (WHO), about $16 \%$ of hearing loss worldwide is attributable to occupational noise exposure. Military personnel, especially those in combat arms are particularly vulnerable to noise induced hearing loss (NIHL) as a result of routine exposure to firearms and heavy machinery noise (e.g. tanks, heavy vehicles, aircraft etc.). ${ }^{1,2}$ WHO recommends that impulse noise must not exceed 140dB. For military personnel, hearing protection is recommended since the weapons currently in use clearly exceed the damage risk criteria for impulse noise. ${ }^{3}$ An automatic gun produces noise levels of 174 $\mathrm{dB}, 105-\mathrm{mm}$ howitzers produce $194 \mathrm{~dB}$, field cannons produce $188 \mathrm{~dB}$, antitank guns produce $185 \mathrm{~dB}$ and small arms produce more than $150 \mathrm{~dB}$ sound. Hearing Protection Devices (HPDs) attenuate localization cues and provide a sound attenuation of only about $50 \mathrm{~dB}$ and make the commands and instructions inaudible. ${ }^{4,5}$ Unilateral hearing protection when using hand held weapons has been demonstrated to be sufficient to substantially reduce risk of impulse noise induced hearing loss. ${ }^{6}$ 
About $15 \%$ of Finnish conscripts have been reported to suffer from hearing impairment during their compulsory military service. ${ }^{7}$ In a 2011 study, 55.8\% Belgian military personnel were reported to be suffering from hearing loss attributable to weapon noise exposure. ${ }^{1}$ In 2006, hearing loss was the most prevalent disability attributable to military service in the US. More than $\$ 1.6$ billion was spent on rehabilitation of such personnel during that year. ${ }^{4}$ Hearing loss in military personnel has serious implications for both the personnel and the government. The personnel suffering from NIHL are rendered unfit for regular military duties. The government has to rehabilitate these personnel and also foot pension bills. Pure tone audiometry can detect hearing loss only after it has occurred. Thus, a screening strategy aimed at detecting cochlear impairment at a preclinical stage is desirable.

Otoacoustic emissions (OAEs) are an attractive tool for use as a screening procedure because they are objective, can be carried out in a few minutes and the results are reproducible. ${ }^{8}$ Distortion product otoacoustic emissions (DPOAEs) can measure cochlear function at higher frequencies than transient evoked otoacoustic emission (TEOAEs). ${ }^{9,10}$ On the other hand, TEOAEs have been proven to be an objective tool to screen adults for NIHL. ${ }^{11}$ It has been reported that since the DPOAEs are present at greater audiometric thresholds, TEOAEs may be preferable for screening purposes, whereas DPOAEs may be more valuable for monitoring cochlear changes clinically. DPOAE amplitudes have been shown to be reduced after firing practice. ${ }^{10,12,13}$ TEOAEs and DPOAEs, therefore, complement each other.

OAE amplitudes have been observed to be lower in noise exposed subjects with normal hearing thresholds than the non-exposed normal hearing subjects. ${ }^{14-16}$ A study on Brazilian military personnel reported poorer TEOAE parameters in noise exposed normal hearing subjects visà-vis non exposed normal hearing subjects. However, the study was silent on the impact on DPOAEs. ${ }^{17}$ DPOAEs have been observed to decrease in noise exposed individuals with normal audiograms at the community level. However, DPOAEs have still not been proven to be reliable for individual follow up. ${ }^{18}$

The current study aims to analyse the utility of TEOAEs and DPOAEs to detect cochlear damage due to chronic exposure to firearm noise in Indian military personnel at a preclinical stage and hence warn about an impending hearing handicap in a vulnerable population.

\section{METHODS}

This cohort study was carried out in the department of ENT and Head and Neck Surgery of the author's institute from May 2004 to Apr 2005. The subjects included in the study (civilians as well as Army personnel) were selected from among the patients attending the ENT out-patient department and individuals working in the institute. All participants were informed about the purpose of the study and were assured of complete confidentiality of the results. Informed written consent was taken from all subjects prior to taking the observations. All the subjects were male below 35 years of age to minimize the confounding effect of presbyacusis. Among military personnel, only soldiers and officers of the Indian Army were included in the study. Personnel of the Indian Airforce, Indian Navy and paramilitary forces were not included. The military personnel were included irrespective of their job profile and the branch of the army to which they belonged since all army personnel receive firearm training. The regularity of training varies according to job profile and branch. The civilians subjects were included in the study only if they had no history of hearing loss or history of routine exposure to impulse or machinery noise.

All the chosen subjects were then subjected to detailed history taking and examination, particularly of the ears. At this stage, subjects having any otological abnormality were excluded from the study. The subjects then underwent pure tone audiometry in the sound attenuated room in the audiology unit of ENT out-patient department. Frequencies assessed included 0.25, 0.5, 1, 2, 3,4 and $6 \mathrm{kHz}$. Subjects having audiometric thresholds above $25 \mathrm{~dB}$ at any of the assessed frequencies were classified as having hearing loss. At this stage, subjects with conductive or mixed hearing loss were excluded from the study. All civilians having sensorineural hearing loss were also excluded from the study. The civilians finally included in the study after pure tone audiometry formed the Control Group 1. The military personnel having sensorineural hearing loss (SNHL) were excluded if the hearing loss was likely to be of causes other than noise exposure. Subjects with acute acoustic trauma were also excluded from the study. The remaining military personnel with hearing loss were included in Control Group 2. The military personnel with more than three years military service and having hearing thresholds below $25 \mathrm{~dB}$ at all tested frequencies, defined as normal hearing, formed the Study Group. By these criteria, only control group 2 had hearing loss. The data for all the subjects was recorded on a proforma designed for the study. The data was recorded as per response of each ear. If one ear of a military personnel had SNHL and the other had normal hearing, then the ear with SNHL was included in Control Group 2, whereas the normal hearing ear was included in the Study Group. In case of civilian subjects, the ear with hearing loss was excluded from the study, whereas the other ear was included in Control Group 1.

The subjects finally included in the three groups were subjected to diagnostic TEOAEs and DPOAEs using ILO 292 DP Echoport instrument supplied by Otodynamics Ltd. U.K. using the ILO version 5 software, in a sound attenuated room after ensuring that the patient's ear is free of wax, debris or discharge and the tympanic membrane is intact. The TEOAE parameters assessed 
included response at five equal frequency bands centred at $1,1.5,2,3$ and $4 \mathrm{kHz}$ expressed as Sound to Noise Ratio (SNR), overall TEOAE amplitude and TEOAE spectrum range calculated as the difference between the first and the last TEOAE peak. A standard nonlinear biphasic click stimulus of $1 \mathrm{~ms}$ duration at $84 \mathrm{~dB}$ peak and with a band width ranging from $500 \mathrm{~Hz}$ to $6000 \mathrm{~Hz}$ was applied at an interval of $20 \mathrm{~ms}$. The stimulus was Noise rejection did not exceed 50dB. The accumulated responses were then automatically tested for signal validity by checking for non-linearity and reproducibility. No definite criteria for acceptable level of reproducibility was laid down. The final results were then displayed as waveforms and frequency spectrum. TEOAE level more than or equal to $3 \mathrm{~dB}$ at each frequency, reproducibility more than or equal to $65 \mathrm{~dB}$ and overall TEOAE level more than or equal to $6 \mathrm{~dB}$ were considered normal.

The DPOAEs were measured by simultaneously presenting two frequencies $\mathrm{f} 1$ and $\mathrm{f} 2$ at the default frequency ratio 1:1.22 and an equal amplitude of $70 \mathrm{~dB}$. The resultant DPOAEs at a frequency of $2 \mathrm{f} 2-\mathrm{f} 1$ were recorded corresponding to $\mathrm{f} 2$ frequencies of $1,2,3,4 \& 6$ $\mathrm{kHz}$ relative to the noise floor or SNR.

The data for all three groups was compiled on excel worksheets and was analyzed using GraphPad InStat 3 software. Since many recorded parameters did not show normal distribution, the Mann Whitney $U$ test was used to test for significance between means. The means of the results of study group were compared with those of both the control groups to analyze for significant differences.

\section{RESULTS}

A total of 75 subjects (150 ears) were tested. Out of these, 114 ears belonged to Indian Army personnel. Each of the three groups included 50 ears each. Forty percent subjects in control group 1 were between and 20 to 25 years of age. Subjects of study group and control group 2 belonged to higher age group. Only two subjects below 20 years of age were included in the study (Table 1).

Table 1: Age distribution.

\begin{tabular}{|l|lll|}
\hline $\begin{array}{l}\text { Age } \\
\text { group } \\
\text { (years) }\end{array}$ & $\begin{array}{l}\text { No. of ears }(\%) \\
\text { Study } \\
\text { group } \\
(\mathbf{n = 5 0 )}\end{array}$ & $\begin{array}{l}\text { Control } \\
\text { group 1 } \\
(\mathbf{n = 5 0})\end{array}$ & $\begin{array}{l}\text { Control } \\
\text { group 2 } \\
(\mathbf{n = 5 0 )}\end{array}$ \\
\hline$\leq 20$ & $0(0 \%)$ & $2(4 \%)$ & $0(0 \%)$ \\
\hline $20-25$ & $6(12 \%)$ & $20(40 \%)$ & $10(20 \%)$ \\
\hline $26-30$ & $24(48 \%)$ & $14(28 \%)$ & $18(36 \%)$ \\
\hline $31-35$ & $20(40 \%)$ & $14(28 \%)$ & $22(44 \%)$ \\
\hline
\end{tabular}

Most of the ears in the study group had 6-10 year history of noise exposure, whereas most of the subjects in control group 2 had more than 15 years of noise exposure. As per inclusion criteria, subjects of control group 1 had no history of regular noise exposure (Table 2).
Table 2: Duration of noise exposure.

\begin{tabular}{|lll|}
\hline $\begin{array}{l}\text { Duration of } \\
\text { exposure } \\
\text { (years) }\end{array}$ & $\begin{array}{l}\text { No. of ears }(\%) \\
\text { Study } \\
\text { group } \\
(\mathbf{n = 5 0 )}\end{array}$ & $\begin{array}{l}\text { Control } \\
\text { group 2 } \\
(\mathbf{n = 5 0})\end{array}$ \\
\hline$\leq 5$ & $14(28 \%)$ & $6(12 \%)$ \\
\hline $6-10$ & $22(44 \%)$ & $14(28 \%)$ \\
\hline $11-15$ & $14(28 \%)$ & $6(12 \%)$ \\
\hline$>15$ & $0(0 \%)$ & $24(48 \%)$ \\
\hline
\end{tabular}

Among the soldiers of the Indian Army included in the study, 7 (14 ears) had a history of firearm noise exposure below three years. They were included in control group 1 . Thirty six subjects in this group were civilians. The exact quantum of noise exposure of the soldiers could not be assessed because of the variety of weapons used by each soldier at different times in their careers and their job profile. All the individuals gave a history of using hand held weapons like rifles, pistols, light machine guns, carbines etc. in both the noise exposed groups. Two individuals each from study group and control group 2 .

None of the subjects gave a history of hearing loss. In control group 2, hearing loss was detected clinically in 12 ears. In the rest, hearing loss was detected on pure tone audiometry (Table 6). All subjects in this group had bilateral sensorineural hearing loss. But 10 subjects had asymmetrical hearing loss.

\section{TEOAE results}

TEOAE level (Table 3, Table 7): The mean TEOAE level at all measured frequencies was significantly more in the control group 1 in comparison with the study group except at $3 \mathrm{kHz}$. In contrast, the mean TEOAE level of the study group was significantly more than that of control group 2 in all frequencies except at 1 and $3 \mathrm{kHz}$. Similar trends were observed for overall TEOAE level.

Spectrum range (Table 3 and 4): There was no significant difference in the TEAOE spectrum range results for study group and control group 1. However, the mean spectrum of the study group was significantly greater than the control group 2. Also, the TEOAE spectrum was wide in only 8 ears in control group 2 compared with 33 for study group.

\section{DPOAE results}

Responses at all frequencies (Table 5): There was no significant difference between DPOAE amplitudes of study group and control group 1 at any frequency. DPOAE amplitude of control group 2 was significantly less than study group in only three out of five measured frequencies. 
Table 3: TEOAE results.

\begin{tabular}{|llllll|}
\hline TEOAE parameters & $\begin{array}{l}\text { Control group 1 } \\
\text { (Mean } \pm \text { standard } \\
\text { deviation) }(\mathbf{d B})\end{array}$ & $\begin{array}{l}\text { Study group } \\
\text { (Mean } \pm \text { standard } \\
\text { deviation) }(\mathbf{d B})\end{array}$ & $\begin{array}{l}\text { Control group 2 } \\
\text { (Mean } \pm \text { standard } \\
\text { deviation) }\end{array}$ & $\begin{array}{l}\text { Significance } \\
\text { (Control group1: } \\
\text { Study group) }\end{array}$ & $\begin{array}{l}\text { Significance } \\
\text { (Control group } \\
\text { 2: Study group) }\end{array}$ \\
\hline $1 \mathrm{kHz}$ & $8.39 \pm 5.66$ & $4.54 \pm 5.38$ & $3.51 \pm 4.80$ & 0.0025 & 0.3662 \\
\hline $1.5 \mathrm{kHz}$ & $11.67 \pm 6.61$ & $9.5 \pm 6.67$ & $5.95 \pm 5.92$ & 0.0364 & 0.0094 \\
\hline $2 \mathrm{kHz}$ & $10.42 \pm 5.81$ & $8.46 \pm 7.06$ & $4.37 \pm 4.77$ & 0.0284 & 0.0018 \\
\hline $3 \mathrm{kHz}$ & $6.83 \pm 5.05$ & $5.5 \pm 6.20$ & $3.49 \pm 4.37$ & 0.2057 & 0.1172 \\
\hline $4 \mathrm{kHz}$ & $6.44 \pm 5.54$ & $3.96 \pm 5.34$ & $1.73 \pm 3.51$ & 0.0085 & 0.0427 \\
\hline Overall TEOAE level & $9.53 \pm 4.90$ & $6.92 \pm 5.54$ & $5.17 \pm 4.11$ & 0.0297 & 0.0942 \\
\hline FLP & $3.52 \pm 0.92$ & $3.30 \pm 1.17$ & $2.42 \pm 0.96$ & 0.4091 & $<0.0001$ \\
\hline Spectrum & $2.61 \pm 0.94$ & $2.37 \pm 1.17$ & $1.32 \pm 1.03$ & 0.2355 & $<0.0001$ \\
\hline
\end{tabular}

Table 4: Spectrum range.

\begin{tabular}{|llll|}
\hline & No. of ears (\%) & & \\
\cline { 2 - 4 } & Wide (>2 kHz) & Narrow $(\leq \mathbf{2} \mathbf{~ k H z )}$ & No response \\
\hline Control group 1 & $35(70 \%)$ & $15(30 \%)$ & 0 \\
\hline Study group & $33(66 \%)$ & $16(32 \%)$ & $1(2 \%)$ \\
\hline Control group 2 & $8(16 \%)$ & $34(68 \%)$ & $8(16 \%)$ \\
\hline
\end{tabular}

Table 5: DPOAE results.

\begin{tabular}{|llllll|}
$\begin{array}{l}\text { DPOAE } \\
\text { frequency }\end{array}$ & $\begin{array}{l}\text { Control group 1 } \\
\text { (Mean } \pm \text { standard } \\
\text { deviation) }(\mathbf{d B})\end{array}$ & $\begin{array}{l}\text { Study group } \\
\text { (Mean } \pm \text { standard } \\
\text { deviation) }(\mathbf{d B})\end{array}$ & $\begin{array}{l}\text { Control group 2 } \\
\text { (Mean } \pm \text { standard } \\
\text { deviation) }(\mathbf{d B})\end{array}$ & $\begin{array}{l}\text { Significance } \\
\text { (Control group1: } \\
\text { Study group) }\end{array}$ & $\begin{array}{l}\text { Significance } \\
\text { (Control group } \\
\text { 2: Study group) }\end{array}$ \\
\hline $1 \mathrm{kHz}$ & $9.36 \pm 4.09$ & $7.17 \pm 5.34$ & $5.71 \pm 6.68$ & 0.0926 & 0.3362 \\
\hline $2 \mathrm{kHz}$ & $10.15 \pm 4.63$ & $8.47 \pm 5.71$ & $6.57 \pm 7.65$ & 0.2525 & 0.1903 \\
\hline $3 \mathrm{kHz}$ & $10.20 \pm 3.53$ & $9.42 \pm 6.88$ & $6.49 \pm 7.01$ & 0.9313 & 0.0093 \\
\hline $4 \mathrm{kHz}$ & $9.56 \pm 4.65$ & $8.45 \pm 7.47$ & $3.98 \pm 6.48$ & 0.9231 & 0.0002 \\
\hline $6 \mathrm{kHz}$ & $5.65 \pm 7.51$ & $6.23 \pm 8.66$ & $-2.32 \pm 9.34$ & 0.4608 & $<0.0001$ \\
\hline
\end{tabular}

Table 6: Degree of hearing loss in control group 2.

\begin{tabular}{|ll|}
\hline Degree of hearing loss & $\begin{array}{l}\text { No. of } \\
\text { ears (\%) }\end{array}$ \\
\hline Mild & $7(14 \%)$ \\
\hline Moderate & $20(40 \%)$ \\
\hline Moderately severe & $23(46 \%)$ \\
\hline
\end{tabular}

Table 7: No. of ears with overall TEOAE level $\geq 6 \mathrm{~dB}$.

\begin{tabular}{|l|l|}
\hline & $\begin{array}{l}\geq \mathbf{6 d B} \text { No. of } \\
\text { ears }(\%)\end{array}$ \\
\hline Control group 1 & $39(78 \%)$ \\
\hline Study group & $30(60 \%)$ \\
\hline Control group 2 & $20(40 \%)$ \\
\hline
\end{tabular}

\section{DISCUSSION}

The current study shows that the mean TEOAE levels of the study group were less than control group 1 at all frequencies except at $3 \mathrm{kHz}$. The mean overall TEOAE amplitude was also reduced. However, there was no significant difference in mean FLP and mean spectrum range between the two groups. The mean TEOAE levels of the study group, on the other hand, were significantly higher than those of control group 2 at 1.5, 2 and $4 \mathrm{kHz}$. The difference between mean overall TEOAE amplitude was marginally significant. However, spectrum range was significantly higher in the study group. The results for DPOAE were quite different. There was no significant difference between the mean DPOAE amplitudes of study group and control group 1 at any of the tested frequencies. But the DPOAE amplitudes of almost all frequencies of control group 2 were significantly less than those of study group.

There were very few subjects below 20 years of age. A minimum of 3 years service was kept as a selection criterion in the current study. The upper age limit was kept 35 years to minimize the confounding effect of presbyacusis. Most of the subjects were 26-35 years of age. Only male subjects were included in the study because the number of women in the Indian armed forces is very low and the sample size may not have been representative. Most of the ears in the study group had a 
6-10 year history of noise exposure whereas, most of those in control group 2 had more than 15 years of exposure. Incidence and severity of hearing loss has been shown to increase with age and number of years of military service and hence, noise exposure. ${ }^{1}$ On PTA testing, all subjects in control group 2, except ten, had bilaterally symmetrical sensorineural hearing loss. This was probably because apart from impulse noise from small arms, subjects were exposed to noise from other sources too. In the military personnel routinely using only small arms, laterality of hearing loss depends on head position during firing. ${ }^{6}$ Most of the subjects had moderate to moderately severe hearing loss. They were asymptomatic probably because in most of them only higher frequencies were involved.

Mean TEOAE amplitude of study group is less than that of corresponding frequencies of control group 1 at all except one frequency, and more than those of control group 2 at three out of five tested frequencies. TEOAE amplitudes at $4 \mathrm{kHz}$ were the lowest. As a drawback of TEOAEs, frequencies higher than $4 \mathrm{kHz}$ could not be tested. The overall TEOAE amplitude was also reduced in the study group compared to control group 1 and higher than control group 2 . These results are similar to earlier studies on noise exposed subjects. ${ }^{19,20}$ Soldiers too have been reported to have lower amplitudes even though hearing thresholds might be normal. ${ }^{21,22}$ The presence of TEOAEs in NIHL ears can be considered to indicate hearing better than $20 \mathrm{~dB} \mathrm{HL}$ at the corresponding frequency (Attias et al., 1995). ${ }^{10}$

On further analysis of TEOAE response, spectrum range did not vary significantly between study group and control group 1 , but was significantly less in control group 2 than the study group. Most of the ears in study group and control group 1 had a wide spectrum range (66\% and $70 \%$ respectively). However, in control group 2 , the hearing loss group, most of the ears had a narrow spectrum range $(68 \%)$. These results were along expected lines in ears with impaired hearing but not in ears exposed ears with normal hearing. This trend was observed in previous studies. ${ }^{11,23}$ Variations of TEOAE amplitudes are the most commonly used parameter to screen ears with hearing loss. Spectrum range provides additional information about cochlear impairment and may be significant only if there is greater damage than in normal hearing ears. Hence, TEOAEs have proven to be useful to screen ears susceptible to development of NIHL in the current study.

Mean DPOAE responses of study group were not significantly different from control group 1 at any frequency. However, those of control group 2 are significantly less than study group at all except one measured frequency. Previous studies have demonstrated the utility of DPOAEs in detecting early cochlear damage unlike the current study. ${ }^{19,24-26}$ Balatsouras also demonstrated efficacy of DPOAEs in detecting cochlear damage in subjects with NIHL beyond the frequencies suggested as abnormal by PTA. ${ }^{27}$ The DPOAE results were unexpected with regard to normal hearing ears with and without hearing loss. Even so, similar results have also been reported previously, where TEOAEs have been observed to be more sensitive to preclinical NIHL than DPOAEs. ${ }^{28}$ In a review article too, Marshall et al. have suggested that TEOAEs might be superior to DPOAEs in detecting subclinical NIHL. ${ }^{29}$ Though not significant, the mean DPOAE amplitude of study group was lower than that of control group 1 at all frequencies except $6 \mathrm{kHz}$. These results must not be rejected outright. The reasons for such results are complex. TEOAEs have been classified as reflection-source OAEs, whereas DPOAEs are distortion-source OAEs. ${ }^{30}$

Since the reflection-source and distortion-source OAEs have different origins, the same cochlear pathology might differently impact the two types. It has been suggested that reflection-source OAEs like TEOAEs might be the OAEs of choice for certain pathologies like NIHL owing to their greater sensitivity to changes in amplication. ${ }^{31}$ This might be the reason for greater sensitivity of TEOAEs in the current study as well. The DPOAE results might be useful to screen ears with hearing loss but not ears susceptible to NIHL.

\section{CONCLUSION}

The study reveals that TEOAEs might be useful in distinguishing between green ears and ears chronically exposed to impulse noise with and without hearing loss. DPOAEs did not prove useful in distinguishing between green ears and chronically impulse noise exposed normal hearing ears. However, they proved efficient in distinguishing normal hearing from hearing loss ears. Thus, though OAEs show promise as screening tool for early cochlear damage in the armed forces, conclusive evidence for the most appropriate OAE for the purpose is still evasive. The otoacoustic emissions are a step closer to the ideal test for hearing in that they are highly repeateable and sensitive to minor cochlear damage. ${ }^{32}$ Further research is also needed to accurately distinguish soldiers who need regular monitoring for noise induced cochlear damage. Such research needs a larger sample size and must distinguish between the predominant noise sources the soldier is exposed to during his military service.

\section{ACKNOWLEDGMENTS}

The author acknowledges the contribution of Indian Council of Medical Research (ICMR) in partially funding this study (Project number 2003-04840). I am grateful to Prof SS Panwar and Prof PS Sukthankar for their guidance and motivation for the study. I also take this opportunity to thank the staff of the Department of ENT, Army Hospital (Research and Referral), New Delhi. I offer my sincere gratitude to all the subjects who volunteered for participation in the study. 
Funding: The study was funded by Indian Council of Medical Research (ICMR)

Conflict of interest: None declared

Ethical approval: The study was approved by the institutional ethics committee

\section{REFERENCES}

1. Collee A, Legrand C, Govaerts B, Veken PV, De Boodt F, Degrave E. Occupational exposure to noise and the prevalence of hearing loss in a Belgian military population: a cross-sectional study. Noise Health. 2011;13:64-70.

2. Fitzpatrick DT. An analysis of noise-induced hearing loss in Army helicopter pilots. Aviat Space Environ Med. 1988;59:937-41.

3. Johnson DL, Papadopoulos P, Watfa N, Takala J. Exposure criteria, occupational exposure levels. In: Goelzer B, Hansen CH, Sehrndt CA, eds. Occupational Exposure to Noise: Evaluation, Prevention and Control. Geneva (SZ): World Health Organization; c2001: Chapter 4.

4. Saunders GH, Griest SE. Hearing loss in veterans and the need for hearing loss prevention programs. Noise Health. 2009;11:14-21.

5. MedicineNet. We bring doctors knowledge to you. California: MedicineNet, Inc; c1996-2012. Noise Induced Hearing Loss and its Prevention; 21 July 2009. Available at: http://www.medicinenet.com/noise_induced_hearin g_loss_and_its_prevention/page5.htm\#what_are_the _regulations_regarding_on-the-

job_exposure_to_noise. Accessed 31 December 2012.

6. Moon IS. Noise-induced hearing loss caused by gunshot in South Korean military service. Mil Med. 2007; 172:421-5.

7. Savolainen S, Kuokkanen JT, Lehtomäki KM. Influence of strict regulations on the use of hearing protectors in the Finnish Defence Forces. Mil Med. 1999;164:824-6.

8. Seixas NS, Kujawa SG, Norton S, Sheppard L, Neitzel R, Slee A. Predictors of hearing threshold levels and distortion product otoacoustic emissions among noise exposed young adults. Occup Environ Med. 2004;61:899-907.

9. Attias J, Bresloff I, Reshef I, Horowitz G, Furman V. Evaluating noise induced hearing loss with distortion product otoacoustic emissions. $\mathrm{Br} \quad \mathrm{J}$ Audiol. 1998;32:39-46.

10. Attias J, Furst M, Furman V, Reshef I, Horowitz G, Bresloff I. Noise-induced otoacoustic emission loss with or without hearing loss. Ear Hear. 1995; 16:612-8.

11. Reshef I, Attias J, Furst M. Characteristics of clickevoked otoacoustic emissions in ears with normal hearing and with noise-induced hearing loss. $\mathrm{Br} \mathrm{J}$ Audiol. 1993;27:387-95.
12. Probst R, Harris FP. Transiently evoked and distortion-product otoacoustic emissions. Comparison of results from normally hearing and hearing-impaired human ears. Arch Otolaryngol Head Neck Surg. 1993;119:858-60.

13. Balatsouras DG, Tsimpiris N, Korres $\mathrm{S}$, Karapantzos I, Papadimitriou N, Danielidis V. The effect of impulse noise on distortion product otoacoustic emissions. Int J Audiol. 2005;44:440-9.

14. Marshall L, Lapsley Miller JA, Heller LM, Wolgemuth KS, Hughes LM, Smith SD, et al. Detecting incipient inner-ear damage from impulse noise with otoacoustic emissions. J Acoust Soc Am. 2009;125:995-1013.

15. Lapsley Miller JA, Marshall L, Heller LM, Hughes LM. Low-level otoacoustic emissions may predict susceptibility to noise-induced hearing loss. J Acoust Soc Am. 2006;120:280-96.

16. Torre P 3rd, Howell JC. Noise levels during aerobics and the potential effects on distortion product otoacoustic emissions. J Commun Disord. 2008;41:501-11.

17. Heupa AB, Gonçalves CG, Coifman H. Effects of impact noise on the hearing of military personnel. Braz J Otorhinolaryngol. 2011;77:747-53.

18. Seixas NS, Goldman B, Sheppard L, Neitzel R, Norton S, Kujawa SG. Prospective noise induced changes to hearing among construction industry apprentices. Occup Environ Med. 2005;62:309-17.

19. Sulaiman AH, Husain R, Seluakumaran K. Evaluation of early hearing damage in personal listening device users using extended highfrequency audiometry and otoacoustic emissions. Eur Arch Otorhinolaryngol. 2014;271(6):1463-70.

20. Hamdan AL, Abouchacra KS, Zeki Al Hazzouri AG, Zaytoun G. Transient-evoked otoacoustic emissions in a group of professional singers who have normal pure-tone hearing thresholds. Ear Hear. 2008;29:360-77.

21. Konopka W, Olszewski J, Pietkiewicz P, Mielczarek M. Impulse noise influence on hearing. Pol Merkur Lekarski. 2005;19:296-7.

22. Konopka W, Pawlaczyk-Luszczynska M, SliwinskaKowalska M, Grzanka A, Zalewski P. Effects of impulse noise on transiently evoked otoacoustic emission in soldiers. Int J Audiol. 2005;44:3-7.

23. Kowalska S, Sułkowski W. Measurements of clickevoked otoacoustic emission in industrial workers with noise-induced hearing loss. Int J Occup Med Environ Health. 1997;10:441-59.

24. Konopka W, Olszewski J, Pietkiewicz P, Mielczarek M. Distortion product otoacoustic emissions before and after one year exposure to impulse noise. Otolaryngol Pol. 2006;60:243-7.

25. Satar B, Kapkin O, Ozkaptan Y. Evaluation of cochlear function in patients with normal hearing and tinnitus: a distortion product otoacoustic emission study. Kulak Burun Bogaz Ihtis Derg. 2003; $10: 177-82$. 
26. Atchariyasathian V, Chayarpham S, Saekhow S. Evaluation of noise-induced hearing loss with audiometer and distortion product otoacoustic emissions. J Med Assoc Thai. 2008;91:1066-71.

27. Balatsouras DG. The evaluation of noise-induced hearing loss with distortion product otoacoustic emissions. Med Sci Monit. 2004;10:CR218-22.

28. Lapsley Miller JA, Marshall L, Heller LM. A longitudinal study of changes in evoked otoacoustic emissions and pure-tone thresholds as measured in a hearing conservation program. Int $\mathbf{J}$ Audiol. 2004;43:307-22.

29. Marshall L, Lapsley Miller JA, Heller LM. Distortion-product otoacoustic emissions as a screening tool for noise-induced hearing loss. Noise Health. 2001;3:43-60.
30. Lewis, James Douglas. The origin of short-latency transient-evoked otoacoustic emissions. $\mathrm{PhD}$ (Doctor of Philosophy) thesis, University of Iowa; 2013. Available at: http://ir.uiowa.edu/etd/5013.

31. Shera CA. Mechanisms of mammalian otoacoustic emission and their implications for the clinical utility of otoacoustic emissions. Ear Hear. 2004 Apr;25(2):86-97. Review. Erratum in: Ear Hear. 2004;25:308.

32. Hall AJ, Lutman ME. Methods for early identification of noise-induced hearing loss. Audiology. 1999;38:277-80.

Cite this article as: Bhatia A. Otoacoustic emissions in detection of pre-clinical noise induced cochlear damage in military personnel. Int J Otorhinolaryngol Head Neck Surg 2015;1:58-64. 